\title{
Por uma didática de leitura e produção textual: uma proposta de ensino com o gênero Relato Pessoal
}

\author{
For a didactic of reading and textual production: a teaching proposal with the genre \\ Personal Reporting
}

\author{
Oscarina de Castro Silva Fontenele* \\ Universidade Estadual do Piauí \\ Teresina, Piauí, Brasil
}

\author{
Pedro Rodrigues Magalhães Neto ${ }^{* *}$ \\ Universidade Estadual do Piani \\ Teresina, Piauí, Brasil
}

\begin{abstract}
Resumo: Este artigo discute a importância e a necessidade do trabalho com gêneros textuais na escola. Mais especificamente, traz uma sugestão de ensino que contempla os eixos de leitura e produção textual com o gênero relato pessoal "Banhos de Mar", de Clarice Lispector, pensada como proposta de intervenção para alunos de $6^{\circ}$ ano do ensino fundamental de uma escola estadual pública da cidade de Parnaíba-PI. Como questões norteadoras temos: "Como ensinar os alunos a produzirem um determinado gênero textual?”; “O que significa tomar o gênero textual como objeto de ensino?" O objetivo central deste artigo é apresentar uma sequência didática com o gênero relato pessoal, como material didático pensado para ampliar a competência dos alunos em leitura e produção textual. Objetiva-se, ainda, refletir sobre a natureza processual da escrita e estimular a didatização das práticas de produção textual. Para fundamentar este trabalho e alcançar os objetivos propostos, recorremos, principalmente, a Bakhtin(2011), aos PCN(BRASIL,1998), à BNCC(BRASIL, 2017), a Dolz, Noverraz e Schneuwly (2004), a Lopes-Rossi (2006), a Marcuschi (2008), a Passarelli(2012), entre outros. Com a discussão estabelecida nesse texto, esperamos munir os professores de conhecimentos teóricos e atividades práticas sobre as questões analisadas a fim de que conduzam as atividades de leitura e produção textual de forma didatizada.
\end{abstract}

\section{Palavras-chave: Leitura. Produção Textual. Relato Pessoal. Sequência Didática}

\begin{abstract}
This article discusses the importance and necessity of working with textual genres in school. More specifically, it brings a suggestion of teaching that contemplates the axes of reading and textual production with the genus personal account "Baths of the Sea", by Clarice Lispector ", thought as proposal of intervention for 6th grade students of a state school of the city of Parnaíba-PI. As guiding questions we have: "How to teach students to produce a particular textual genre?"; "What does it mean to take the textual genre as an object of teaching?" The main objective of this article is to present a didactic sequence with the genre personal story, as didactic material thought to extend the students' competence in reading and textual production. It is also intended to reflect on the procedural nature of writing and stimulate the didatization of textual production practices. In order to justify this work and to achieve the proposed objectives, we have used Bakhtin (2011), PCN (BRASIL, 1998), BNCC (BRAZIL, 2017), Dolz, Noverraz and Schneuwly (2004), Lopes-Rossi (2006), Marcuschi (2008), Passarelli (2012), among others. With the discussion established in this text, we hope to provide teachers with theoretical knowledge and practical activities on the issues analyzed in order to conduct reading activities and textual production in a didatized way.
\end{abstract}

Keywords: Reading. Textual Production. Personal Report. Didactic Sequence

\footnotetext{
* Mestranda do Profletras, Programa de Pós-Graduação em Letras da Universidade Estadual do Piauí-UESPI. E-mail: oscarinacastro@bol.com.br.

** Doutor em Letras Linguística pela Universidade Federal de Pernambuco - UFPE. Professor do Profletras, Programa de Pós-Graduação em Letras da Universidade Estadual do Piauí-UESPI. E-mail: pedrormneto@bol.com.br.
} 


\section{INTRODUÇÃO}

Nas últimas duas décadas, o sistema educacional brasileiro vem passando por muitas reestruturações de seus fundamentos legais, teóricos e metodológicos. Vive-se um processo de questionamento e revisão do ensino vigente. Novos objetivos de ensino são propostos, mudam-se os objetos de ensino, os pressupostos e procedimentos didáticos. Documentos oficiais foram reformulados e/ou elaborados, como a Lei de Diretrizes e Bases da Educação Nacional - LDB (1996), os Parâmetros Curriculares Nacionais - PCN (BRASIL, 1997; 1998) e, por último, a Base Nacional Comum Curricular - BNCC (BRASIL, 2017), ações que visam melhorar a qualidade da educação nacional.

Nesse contexto de mudanças, os professores de língua materna, de modo geral, têm dúvidas sobre "como" e "o que" ensinar, diante de uma orientação teórico-metodológica que coloca o texto como a unidade básica do ensino e os gêneros textuais como objeto de ensino, contemplando os eixos da oralidade, leitura, análise linguística e produção textual, sem priorizar um mais que outro. Assim, essa reflexão discute questões recorrentes: "Como ensinar os alunos a produzirem um determinado gênero textual?" e "O que significa tomar o gênero textual como objeto de ensino?".

Nessa busca de alternativas, observamos que o professor de língua portuguesa demonstra conceber a língua como uma prática social e, ao estudar sobre gêneros textuais, facilmente entende as características, as funções e exemplos a eles associados. Porém, a mobilização desses saberes no contexto de sala de aula se mostra problemática (OLIVEIRA, 2010); na prática, quando é preciso realizar uma aula de leitura, uma aula de análise linguística e/ou uma aula de produção textual a partir de um gênero textual encontra dificuldades.

Dessa forma, o objetivo deste artigo é apresentar uma sequência didática com o gênero relato pessoal, como material didático destinado a alunos de $6^{\circ}$ do ensino fundamental para ampliar a competência em leitura e produção textual. Objetiva-se, ainda, refletir sobre a natureza processual da escrita e estimular a didatização das práticas de produção textual. A escolha do Relato Pessoal se justifica por ser um gênero no qual o aluno será narrador-personagem, vai escrever, em um nível de informalidade, sobre suas próprias lembranças; além disso, está inserido no contexto de um projeto "Eu também faço história" sugerido pelo livro didático dos alunos.

Para fundamentar este trabalho e alcançar os objetivos propostos, recorremos, principalmente, às considerações sobre gênero discursivo/textual de Bakhtin (2011), dos Parâmetros Curriculares Nacionais - PCN (BARSIL, 1998), da Base Nacional Comum Curricular - BNCC (BRASIL, 2017), Marcuschi (2008) e Dolz e Schneuwly (2004); e as contribuições de Dolz, Noverraz e Schneuwly (2004), Lopes-Rossi (2006), Passarelli (2012) no que se refere a Sequência Didática.

Quanto à estrutura, além desta introdução, este trabalho traz mais cinco seções. Na primeira, refletimos sobre os gêneros textuais como objeto de ensino aprendizagem; na segunda seção, apresentamos conceitos e concepções acerca da metodologia de uma sequência como uma opção de didatizar o ensino de leitura e de produção textual; na terceira, trazemos explicações sobre as características do gênero relato pessoal; na quarta 
seção, apresentamos a descrição de um exemplo de sequência didática com o gênero analisado; e, por fim, as consideração finais.

\section{OS GÊNEROS TEXTUAIS $^{1}$ COMO OBJETO DE ENSINO E APRENDIZAGEM}

O emprego da palavra "gênero" no sentido como é usado nos dias atuais para se referir aos textos que empregamos nas situações cotidianas de comunicação, os denominados "gêneros textuais (ou do discurso)", data da década de 1960 com o desenvolvimento da Linguística Textual.

No âmbito da educação brasileira, a noção de gêneros textuais ganhou evidência com os Parâmetros Curriculares nacionais-PCN, publicados em 1997 (1 $1^{\mathrm{a}}$ a $4^{\mathrm{a}}$ séries) e 1998 ( $5^{\mathrm{a}}$ a $8^{\mathrm{a}}$ séries); complementados, recentemente, pela Base Nacional Comum Curricular-BNCC (BRASIL, 2017); esses documentos oficiais estabelecem que se trabalhe na escola com uma ampla diversidade de gêneros textuais: literários e não literários, orais e escritos. Nesse paradigma de ensino centrado no texto que se concretiza em gêneros textuais, a produção textual dos alunos deixa de ser uma "escrita tipicamente escolar" e passa a ser uma "escrita produzida na escola", mas com significado extraescolar, tanto para quem escreve como para quem lê, pois os textos nascem nas práticas sociais e das interações linguísticas dos indivíduos na sociedade.

$\mathrm{Na}$ busca de uma apropriação que ainda não se efetivou, o professor acaba desenvolvendo um trabalho intuitivo que mistura práticas tradicionais com um discurso pretensamente inovador. Pensar sobre como os professores têm significado essas diretrizes na sala de aula, implica discutir a rica complexidade que envolve não apenas os objetos teóricos - gênero textuais - mas também a aplicação desses conceitos no domínio pedagógico. O que o professor ensina e como ele ensina são consequência da compreensão de que ele tem dos fenômenos linguísticos (OLIVEIRA,2010).

Mikhail Bakhtin (2011) empregou a palavra "gênero" de forma mais didática, declarando que todos os textos empregados socialmente pertencem a algum gênero. Conforme suas próprias palavras:

O emprego da língua efetua-se por meio de enunciados concretos e únicos proferidos pelos integrantes desse ou daquele campo da atividade humana. Esses enunciados refletem as condições e específicas e as finalidades de cada referido campo não só por seu conteúdo (temático) e pelo estilo da linguagem [...], mas acima de tudo por sua construção composicional. (...) cada campo de utilização da língua elabora seus tipos relativamente estáveis de enunciados, aos quais denominamos gêneros do discurso (BAKHTIN, 2011, p. 261-262).

Segundo Bakhtin (2011), o gênero discursivo representa o funcionamento da língua em práticas comunicativas reais e concretas; "aprender a falar é aprender a estruturar

\footnotetext{
1 Neste trabalho, "gêneros discursivos" e "gêneros textual" são termos sinônimos. Em Bakhtin(2011) encontramos a primeira denominação; enquanto que em Marcuschi(2008), Schneuwly e Dolz (2004), a segunda.
} 
enunciados (porque falamos por enunciados e não por orações isoladas e, evidentemente, não por palavras isoladas" (BAKHTIN, 2011, p. 283).

Para Schneuwly e Dolz (2004, p. 64-65) “do ponto de vista do uso e da aprendizagem, o gênero pode, assim, ser considerado um mega instrumento que fornece um suporte para a atividade nas situações de comunicação e uma referência para os aprendizes". Assim, compreendem o gênero textual como uma ferramenta, isto é, como um instrumento, que possibilita exercer uma ação linguística sobre a realidade, para quem o uso de uma ferramenta resulta em dois efeitos de aprendizagem: por um lado amplia as capacidades individuais do usuário; por outro lado, amplia seu conhecimento a respeito do objeto sobre o qual a ferramenta é utilizada.

Marcuschi (2008) afirma que os gêneros são categorias essencialmente sócio históricas sempre em mudanças. Estão situados entre o discurso e o texto e opera como elo, entre as atividades discursivas e o texto numa determinada composição. Para este autor,

Os gêneros textuais são os textos que encontramos em nossa vida diária e que apresentam padrões sociocomunicativos característicos definidos por composições funcionais, objetivos enunciativos e estilos concretamente realizados na integração de forças históricas, sociais, institucionais e técnicas (MARCUSCHI, 2008, p. 155).

Nas palavras de Marcuschi (2008) gêneros textuais designam textos materializados em situações comunicativas reais; fenômenos históricos e vinculados à vida cultural e social. $\mathrm{O}$ autor defende ainda que não há comunicação verbal senão por meio de algum gênero. Da mesma forma, não se pode comunicar verbalmente a não ser por meio de um texto, seja ele oral ou escrito. Trata-se da natureza sócio interativa da linguagem de que "toda a manifestação verbal se dá sempre por meio de textos realizados por algum gênero" (MARCUSCHI, 2008, p. 154).

Na proposta dos PCN (BRASIL, 1998), os gêneros textuais assumem o centro das atividades no ensino de leitura, de compreensão e produção de textos orais e escritos. Esse documento oficial se refere aos gêneros textuais destacando que

Todo texto se organiza dentro de determinado gênero em função das intenções comunicativas, como parte das condições de produção dos discursos, as quais geram usos sociais que os determinam. Os gêneros são, portanto, determinados historicamente, constituindo formas relativamente estáveis de enunciados, disponíveis na cultura. São caracterizados por três elementos: conteúdo temático, construção composicional e estilo (BRASIL,1998, p.21-22).

Em muitas passagens dos PCN (BRASIL, 1998), fica evidente a orientação para que os gêneros textuais sejam utilizados nas práticas de ensino de leitura e produção textual, defendendo os gêneros como fortes aliados no processo de ensino-aprendizagem da língua portuguesa. Em outras palavras, determinam que, nas aulas de língua portuguesa, o ensino de leitura/produção textual se desenvolva com base na noção de gênero. 
Na BNCC (BRASIL, 2017), na esteira do que é proposto nos PCN, o componente Língua Portuguesa amplia o contato dos estudantes com gêneros textuais relacionados a vários campos de atuação, partindo-se de práticas de linguagem já vivenciadas pelos jovens para a ampliação dessas práticas, em direção a novas experiências, assim:

O texto ganha centralidade na definição dos conteúdos, habilidades e objetivos, considerado a partir de seu pertencimento a um gênero discursivo que circula em diferentes esferas sociais de atividade/comunicação/uso da linguagem. Os conhecimentos sobre os gêneros, sobre os textos, sobre a língua, sobre a norma-padrão, sobre as diferentes linguagens devem ser mobilizados em favor do desenvolvimento das capacidades de leitura, produção textual e tratamento das linguagens, de forma a sempre relacionar os textos a seus contextos de produção e o desenvolvimento de habilidades ao uso significativo da linguagem (BRASIL, 2017, p.65).

Dizendo de outro modo, hoje a escola precisa pautar todas as atividades de leitura, produção e análise linguística a partir de gêneros, pois dessa forma oportuniza práticas sociais de uso real da linguagem, em que o texto tem uma finalidade e destinatários definidos.

Exposto todo esse conjunto teórico-metodológico, é preciso responder "O que significa tomar o gênero textual como objeto de ensino?” Uma primeira observação tanto para professores e como para alunos é entender que todo gênero textual se caracteriza por diferentes aspectos: conteúdo, construção composicional, o estilo, a função social e características linguísticas e discursivas. Nesse processo, o princípio maior para ensinar leitura e escrita de forma contextualizada é considerar os gêneros não como um "fim", mas como um "meio". Dizendo de outro modo, ensinar "com" os gêneros e não "sobre" os gêneros; com eles (gêneros) o professor deve articular os três eixos de ensino de língua materna - leitura, produção e análise linguística.

Santos, Mendonça e Cavalcanti (2007) explicam a questão com um exemplo: com questões do tipo "A fábula está organizada em parágrafos?”, “Quantos parágrafos há nesse texto?”, “Que sinal de pontuação indica o início da fala das personagens?” não estamos tomando o gênero como objeto de ensino; se estivesse, a abordagem deveria ir além dos aspectos estruturais presentes no texto. A discussão giraria em torno dos elementos da ordem do social e do histórico, da situação de produção, do estilo, da estrutura composicional e/ou da temática, enfocando aspectos discursivos e a situação de produção dos textos. Para o gênero ser concebido como objeto de ensino devem ser propostas questões de natureza discursiva (a respeito do destinatário, do espaço de circulação e dos objetivos da produção).

A escrita de qualquer gênero precisa ser integralmente planejada, não só quanto ao tema e às características do gênero textual, mas, sobretudo, quanto a sua funcionalidade. Não se trata apenas de permitir o acesso, o manuseio, a leitura ou a produção de diferentes gêneros, mas efetivar um ensino sistemático, explicitando-se "o conhecimento implícito do gênero” (SANTOS; MENDONÇA; CAVALCANTI, 2007)

$\mathrm{Na}$ BNCC (BRASIL, 2017), os eixos já consagrados nos PCN (1998), são denominados práticas de linguagem: oralidade, leitura/escuta, produção (escrita e multissemiótica) e análise linguística. Nela se ressalta que, no ensino fundamental, 
nenhum eixo de estudo da língua deve ser ensinado com o fim em si mesmo, devendo estar envolvidos em práticas de reflexão que permitam aos estudantes ampliarem suas capacidades de uso da língua/linguagens (em leitura e em produção) em práticas situadas de linguagem.

Em acréscimo a isso, é preciso dizer que toda vez que escolhemos um gênero para estudar, temos que considerar que vem junto um conjunto de valores, crenças e saberes associados a cada gênero. Em resumo, na busca para entender os gêneros como objetos de ensino, dá para fazer algumas afirmações:

- Partir de uma situação real e funcional de uso do gênero;

-A escolha do gênero não deve acontecer de modo aleatório, mas articulado com as atividades de leitura e escrita;

-A atenção deve voltar para a constituição linguístico-discursiva do gênero e ao cumprimento de sua função social, às suas peculiaridades e à relação dessas características com o porquê e o para quê;

-A leitura e produção textual, como capacidades de usos da língua/linguagens, passam a ser o centro do ensino de língua, o estudo da gramática tem, pois, um papel coadjuvante para o domínio e uso da linguagem;

-Em uma produção textual, vale mais o processo e não o produto final;

- Rejeitar o ensino de regras, classificações e estruturas como um fim em si mesmo, ensiná-las em função da adequação do registro à situação de comunicação em que o gênero se insere;

-Um trabalho não de análise gramatical, mas de análise linguística, que deve estar a serviço da compreensão e produção dos gêneros textuais;

-Diversidade de gêneros não basta, sem um ensino planejado e sistemático;

-É preciso deixar claro o que se pretende fazer com o texto dos alunos.

\section{O GÊNERO RELATO PESSOAL}

O gênero relato pessoal, embora possua os mesmos elementos da ordem do narrar, como personagens, tempo, espaço e, em dúvida, é narrado por alguém, no agrupamento sugerido por Schneuwly e Dolz (2004) é colocado na ordem do relatar, pertencente ao domínio social da documentação e memorização das experiências humanas.

A escolha se justifica pelas características do gênero, uma narrativa não ficcional, de natureza subjetiva, tem como finalidade o relato, oral ou escrito, de experiências vivenciadas, situadas, predominantemente, no tempo da memória (passado). A linguagem, em geral, é espontânea e informal; é escrito em $1^{\text {a }}$ pessoa; o aluno como narradorpersonagem vai escrever sobre suas lembranças, relatando momentos significativos guardados na memória; além disso está inserido no contexto de um projeto "Eu também faço história" sugerido pelo livro didático dos alunos, que traz o texto "Banhos de mar", de Clarice Lispector.

Ainda se trabalha poucos os gêneros da ordem do relatar no universo escolar

${ }^{2}$ Dolz e Schneuwly (2004) o nomeia "relato de experiência vivida". 
especialmente o relato pessoal. Para Oliveira e Rodrigues (2016), uma das grandes vantagens apontadas para o uso do gênero relato pessoal, como proposta de trabalho em sala de aula, é possibilitar que o aluno se coloque como protagonista no texto que produz; além disso, a produção desse gênero oferece ao professor ter acesso ao universo dos alunos: suas experiências, alegrias, frustrações. Acrescentam ainda que os relatos podem se tornar uma importante ferramenta para que o professor conheça melhor o público discente e possa, assim, criar estratégias mais eficazes para que haja uma aprendizagem significativa.

\section{SEQUÊNCIA DIDÁTICA E O ENSINO DE LEITURA E PRODUÇÃO TEXTUAL: EM BUSCA DE UMA DIDATIZAÇÃO}

Esta seção é iniciada com a pergunta "Como ensinar os alunos a produzirem um determinado gênero textual?” A resposta a esta indagação aponta para a ideia de sequência didática. O termo "Sequência Didática - SD" está associado às pesquisas sobre a aquisição da língua escrita por meio de um trabalho sistemático de ensinar com gêneros textuais desenvolvidos pelos estudiosos: Joaquim Dolz, Michèle Noverraz e Bernard Schneuwly, conhecidos como grupo de Genebra. Em outras palavras, Sequência Didática - SD é um procedimento de o professor planejar e elaborar um material didático com atividades numa sequência para ensinar um gênero textual específico.

Nas palavras de Dolz, Noverraz e Schneuwly (2004, p. 82), "sequência didática é um conjunto de atividades escolares organizadas, de maneira sistemática, em torno de um gênero textual oral ou escrito", proporcionando ao aluno, além de se apropriar das características do gênero, desenvolver sua competência linguística em relação à produção de diferentes gêneros e sua utilidade nas elações sócio comunicativas. Segundo os autores, "uma sequência didática tem, precisamente, a finalidade de ajudar o aluno a dominar melhor um gênero de texto, permitindo-lhe, assim, escrever ou falar de maneira mais adequada numa dada situação de comunicação" (DOLZ, NOVERRAZ E SCHNEUWLY, 2004, p. 83). O esquema abaixo, desenhado pelos autores, é uma representação do processo de trabalho em sequência didática para produção textual, seja oral ou escrita.

Figura 1: Esquema de Sequência Didática

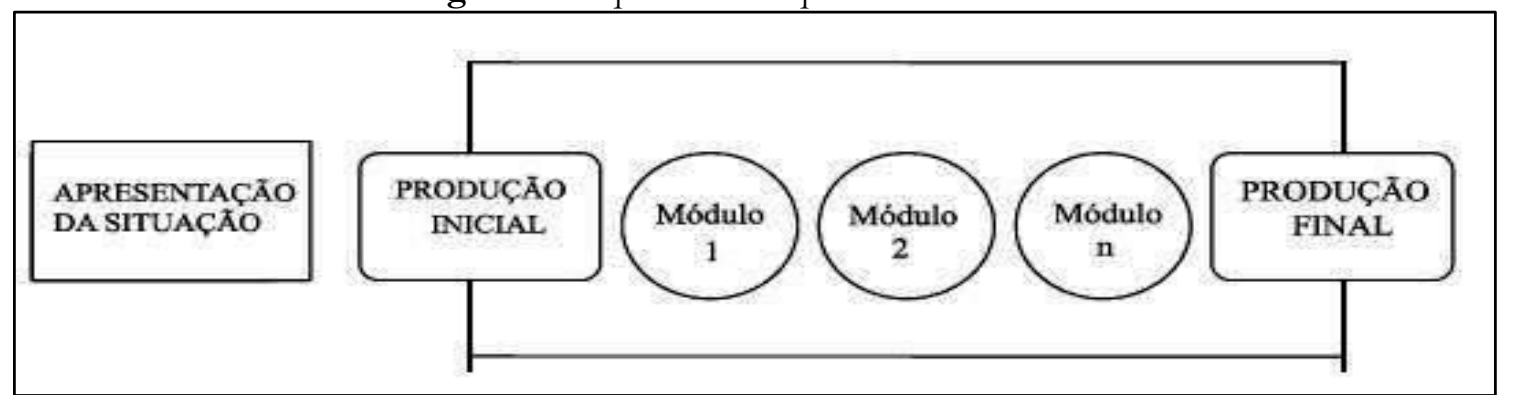

Fonte: Dolz; Noverraz; Schneuwly (2004, p. 83). 
Conforme podemos visualizar na figura, esse esquema de SD compreende uma Apresentação da situação, que visa expor aos alunos um projeto de comunicação, que será realizado na produção final. Essa etapa prepara os alunos para a produção inicial, definida pelos autores como uma primeira tentativa de produção dos gêneros que será, em seguida, trabalhada nos módulos. Segundo os autores, "trata-se de um momento crucial e difícil" na qual se apresentam duas dimensões: "apresentar um "problema de comunicação bem definido" e preparar os conteúdos dos textos que serão produzidos" (DOLZ, NOVERRAZ E SCHNEUWLY, 2004, p. 84-85).

A Primeira produção é o "primeiro lugar de aprendizagem da sequência"; para os alunos que descobrem suas capacidades que sobre o gênero; para o professor constitui momento privilegiado para observação que permite refinar a sequência, modulá-la, adaptá-la, pôr em prática uma avaliação formativa. A partir da primeira produção, a sequência começa a definir o que é preciso ser trabalhado, com a finalidade de desenvolver a capacidade de linguagem dos alunos e, assim, deixá-los preparados para a produção final.

Os Módulos objetivam criar condições para que os alunos possam superar as dificuldades apresentadas na produção inicial. Três pontos principais precisam ser focados para se trabalhar com os módulos: "Trabalhar os problemas" encontrados nas primeiras produções; "variar as atividades e exercícios" e "capitalização as aquisições". A variação das atividades é importante porque dá aos alunos a possibilidade de terem acesso, por diferentes vias, às noções e aos instrumentos necessários para se produzir um gênero.

A sequência é finalizada com uma Produção Final, que dá ao aluno a possibilidade de pôr em prática as noções e os instrumentos elaborados separadamente nos módulos. Essa produção permite, também, ao professor realizar uma avaliação do tipo somativa assentada em critérios elaborados durante a sequência (DOLZ, NOVERRAZ E SCHNEUWLY, 2004).

É preciso dizer que foi a partir das ideias desses autores, fundamentadas nas teorias da interação verbal, da enunciação e dos gêneros textuais (BAKHTIN,1997; 2011), que a metodologia da SD foi conhecida no Brasil, tendo, inclusive, servido de base para os Parâmetros Curriculares Nacionais - PCN (BRASIL, 1997; 1998), nos quais encontramos recomendações para adoção das sequências didáticas:

Módulos didáticos são sequências de atividades e exercícios, organizados de maneira gradual para permitir que os alunos possam, progressivamente, apropriar-se das características discursivas e linguísticas dos gêneros estudados, ao produzir seus próprios textos.

O planejamento dos módulos didáticos parte do diagnóstico das capacidades iniciais dos alunos, permitindo identificar quais instrumentos de ensino podem promover a aprendizagem e a superação dos problemas apresentados (BRASIL, 1998, p. 88),

O modelo de SD esses estudiosos serviu de inspiração para inúmeros autores que o ampliaram ou o redesenharam segundo as realidades e objetivos pretendidos. Assim, nas subseções que seguem, descrevemos outras duas propostas de SD: a de Passarelli (2012) e a de Lopes-Rossi (2006). 


\subsection{SEQUÊNCIA DIDÁTICA SEGUNDO PASSARELLI (2012)}

Para Passarelli (2012, p. 153), "a escrita é um processo e todos os sujeitos possuem habilidades para realizar processos"; explica ainda que "uma proposta de ensino diferenciada, deve ter em conta a escrita como uma tarefa que se realiza em etapas, desenvolvida gradativamente, que exige muita dedicação". Adverte que para um ensino produtivo o aluno precisa ser esclarecido que um bom texto é obtido por uma série de operações e que para cada etapa constitutiva do processo de escrever há procedimentos específicos. A autora afirma que o professor necessita ministrar instruções específicas a respeito da produção textual, evidenciando ao aluno que, para uma produção eficaz, é necessário planejar, escrever um texto provisório, revisar e editar. O modelo de sequência didática pela autora compreende as etapas a seguir:

$1^{\mathrm{a}}$ etapa, Planejamento, consiste em operações de seleção de informações e organização de ideias; "o escritor, a partir do tema, busca informações adequadas, levando em conta o perfil do seu futuro leitor" (PASSARELLI, 2012, p. 153). Para tal, o aluno produtor do texto precisa levar em consideração, também, o destinatário, o objetivo do texto, o gênero escolhido, o seu papel enquanto sujeito produtor, o próprio conteúdo do texto (objeto do texto), o tamanho que o texto irá adquirir e os critérios de avaliação do texto.

$2^{a}$ etapa, Tradução das ideias em palavras, cuida da produção da primeira versão do texto; é escrever as ideias planejadas na primeira fase. "É quando as ideias levantadas passam para o papel, num trabalho que requer a atenção voltada à organização o texto em unidades de base - parágrafos, de acordo com alguns critérios para a sua construção" (PASSARELLI, 2012, p. 157).

$3^{a}$ etapa, Revisão e reescrita, a "re-visão" já define essa etapa: ver de novo. É de proceder à leitura do material produzido, a fim de examinar detalhes referentes ás convenções da escrita, exatidão quanto ao significado; a autora reconhece que, embora essa fase seja fundamental na produção de um texto, a revisão é pouco praticada na escola. Quanto à reescrita, o professor deve desempenhar o papel de correvisor; ao mediar a atividade de reescrita deve apontar as dificuldades tanto de natureza gramatical como também referentes à reflexão e funcionamento no mundo, pois reescrever se constitui numa prática de exploração das possibilidades de realização da língua.

$4^{a}$ etapa, Editoração, consiste em alguns cuidados por parte do aluno escritor para que o texto se torne público, ou seja, seja socializado, para isso é necessário levar em conta o leitor e o suporte em que será veiculado. Segundo a autora é pertinente que o professor deixe claro para o aluno o que se pretende fazer com o produto final.

Passarelli (2012) ainda institui o que ela denominou Guardião do texto, um componente ativo que monitora todo o processo de produção do texto. Segundo a autora (2012, p. 170), "uma espécie de noção intuitiva perpassa todo o processo de escritura, como se fosse um elemento de vigilância" que opera durante todo o processamento do texto". Esse elemento leva em conta aspectos da experiência de vida do escritor: o bom senso do sujeito (realidade concreta), sua intuição (mundo de possibilidades), seus sentimentos (valores pessoais e experiência de vida). 


\subsection{SEQUÊNCIA DIDÁTICA SEGUNDO LOPES-ROSSI(2006)}

Lopes-Rossi (2006) postula que qualquer projeto de leitura e produção textual deve iniciar-se por um estudo do contexto enunciativo do gênero, em outras palavras, das condições de produção e circulação do gênero discursivo. Além dessas caraterísticas, a autora diz que devem ser observados a organização composicional, a organização do texto verbal e não-verbal, aspectos linguísticos, de estilo e marcas enunciativas.

Dessa forma, Lopes-Rossi (2006) apresenta uma proposta de sequência didática composta por três módulos didáticos:

Módulo Didático 1: Leitura para apropriação das características típicas do gênero discursivo. Esse módulo consiste de uma série de atividades de leitura, comentários e discussões de vários exemplares do gênero. O objetivo é levar o aluno a conhecer as características sócio comunicativas e composicionais do gênero, sua organização linguística e seu estilo, para isso são realizadas atividades orais ou escrita desenvolvendo todos os procedimentos descritos anteriormente

O segundo Módulo Didático consiste na produção escrita do gênero de acordo com suas condições de produção típicas. Inclui o planejamento da produção (definição do tema, do esboço geral do texto, da forma de obtenção de informações, dos recursos necessários); a coleta de informações, produção da primeira versão, revisão colaborativa do texto; produção da segunda versão; revisão e versão final do texto, incluindo o suporte para circulação do texto.

O terceiro Módulo Didático, a autora destina para preparar o texto para divulgação ao público, de acordo com a forma típica de circulação do gênero, das produções dos alunos. Nas palavras de Lopes-Rossi (2006, p. 8), "exige-se uma série de providências para efetivar a circulação da produção dos alunos fora na sala de aula e mesmo da escola, de acordo com as necessidade de cada evento de divulgação”.

Assim, analisando os modelos de SD, o que se destaca são as contribuições possíveis de cada um para favorecer o trabalho do professor. A SD de Dolz, Noverraz e Schneuwly (2004) é a pioneira e inspiradora de todos os modelos posteriores, seu escopo principal é o ensino da produção textual. A proposta de Lopes-Rossi (2006) amplia a sequência ao estabelecer módulos para atividades de leitura e para preparar o texto do aluno para publicação; a de Passarelli (2012), além de se preocupar com o momento da divulgação do texto, ainda institui um mecanismo de auto-avaliação, "Guardião do texto".

Conforme Araújo (2013) a ideia central de uma SD é a de modularidade e produto final, por isso dependendo do gênero a ser ensinado, o professor precisa organizar módulos destinados à leitura do gênero, à análise linguística e a produção textual. O que significa dizer que o ensino de um gênero, seja escrito ou oral, implica a realização de procedimentos, atividades e exercícios sistemáticos que envolvem esses três componentes do ensino: leitura/escuta, análise linguística e produção oral/escrita. Sobre a importância de se trabalhar a partir de SD, a autora defende que:

Um trabalho para o ensino de um gênero escrito, à luz do conceito de SD, deve prever módulos para o reconhecimento e a compreensão das características temáticas e composicionais do gênero, outros para o reconhecimento e apreensão das características 
estilísticas do gênero, outros para produção do gênero, o que inclui a reescritura. Os primeiros módulos estariam, assim, a serviço da leitura, os módulos intermediários estariam a serviço da análise linguística e os últimos a serviço da produção do gênero (ARAÚJO, 2013, p. 324-325).

Para finalizar essa seção recuperamos a pergunta lançada inicialmente "Como ensinar os alunos a produzirem um determinado gênero textual?" É certo que uma proposta de produção escrita não pode se resumir a um pedido de "escreva um texto", "seja criativo e elabore um texto com o máximo de trinta de linhas" ou então pedir que um aluno escreva um texto com base, apenas, em uma gravura. É preciso contextualizar, definir as dimensões do texto; nesse sentido, a didatização da produção de um gênero é resultado de um processo que obedece a etapas e que demanda atividades sistematizadas. Por isso, a SD se constitui em uma ferramenta pedagógica muito recomendada para o ensino de gêneros textuais na escola, uma vez que permite que o aluno escreva articulando situações reais de uso da escrita, partindo do seu planejamento até a divulgação de uma versão final evidenciando uma função social.

\section{UMA SEQUÊNCIA DIDÁTICA COM O GÊNERO RELATO PESSOAL}

Com base nos modelos expostos de SD, nos conceitos e recomendações acerca desse procedimento para o ensino de língua portuguesa, esta seção se destina a apresentar um exemplo de sequência didática para o $6^{\circ}$ ano do ensino fundamental com o gênero relato pessoal, com duração de 13 aulas (50 minutos cada). O texto escolhido é "Banhos de Mar", de Clarice Lispector. Composta por três módulos: o primeiro se destina à leitura/interpretação e reflexão sobre a organização linguística do relato pessoal; o segundo, à produção textual; e o terceiro, a preparar a divulgação dos textos.

\section{MÓDULO 1 (5 AULAS): “LENDO, INTERPRETANDO UM RELATO PESSOAL."}

\subsection{Objetivos}

-Ler, de forma autônoma, e apropriar-se da estrutura e da linguagem de texto da ordem do relatar, levando-o a refletir sobre as relações familiares, suas lembranças e experiências;

-Compreender o funcionamento do gênero relato pessoal refletindo sobre aspectos linguísticos e discursivos que o constituem.

\subsection{Motivação}

-Dias antes, o professor deve combinar com os alunos que peçam aos pais, avós etc. que lhes relatem histórias sobre eles: a origem do nome, algum fato engraçado/triste/curioso de quando eram bebês, primeiro dia de aula, alguma viagem; além disso pedir para procurarem fotos de momentos marcante para eles ou de que gostem muito para em um dia marcado trazerem para a aula. 
-Chegado o dia, o professor deve organizar uma roda de conversa com os alunos para que falem dos relatos de seus familiares. Momento que mostrarão as fotos trazidas, explicando a sua importância e o contexto em que foi tirada. Em seguida, solicita-se que façam uma anotação de momentos marcantes de sua vida. As situações devem ser faladas, comparadas e discutidas.

\subsection{Introdução}

-Continuando, o professor pode expor no "datashow" imagens de pessoas na praia com fundo musical do som de ondas do mar (disponível em https://www.youtube.com/watch?v=-fB-3p69rjs).

-Após esse momento, o professor escuta as impressões e sensações dos alunos sobre as imagens. Feito isso, apresenta-se o título do texto "Banhos de Mar", de Clarice Lispector, dizendo que se trata de um relato pessoal; para ativar os conhecimentos prévios, alguns questionamentos podem ser feitos, por exemplo: $O$ título faz lembrar alguma experiência vivida por vocês? O que a autora relatará sobre esse banho?, O que os alunos sabem sobre esse tipo de texto? Se já leram relatos de outras autores? Quem serão os personagens? Quais são suas características?

- Explicar brevemente o que é um relato pessoal.

- Apresentar informações sobre a autora.

\subsection{Leitura}

-Apresentação do texto completo no livro didático para exploração das ilustrações, levantamento de hipóteses e criar expectativas a respeito do enredo.

\section{BANHOS DE MAR}

Meu pai acreditava que todos os anos se devia fazer uma cura de banhos de mar. E nunca fui tão feliz quanto naquelas temporadas de banhos em Olinda, Recife.

Meu pai também acreditava que o banho de mar salutar era o tomado antes do sol nascer. Como explicar o que eu sentia de presente inaudito em sair de casa de madrugada e pegar o bonde vazio que nos levaria para Olinda ainda na escuridão?

De noite eu ia dormir, mas o coração se mantinha acordado, em expectativa. E de puro alvoroço, eu acordava às quatro e pouco da madrugada e despertava o resto da família. Vestíamos depressa e saíamos em jejum. Porque meu pai acreditava que assim devia ser: em jejum.

Saíamos para uma rua toda escura, recebendo a brisa da pré-madrugada. E esperávamos o bonde. Até que lá de longe ouvíamos o seu barulho se aproximando. Eu me sentava bem na ponta do banco: e minha felicidade começava. Atravessar a cidade escura me dava algo que jamais tive de novo. No bonde mesmo o tempo começava a clarear e uma luz trêmula de sol escondido nos banhava e banhava o mundo.

Eu olhava tudo: as poucas pessoas na rua, a passagem pelo campo com os bichosde-pé: “Olhe um porco de verdade!" gritei uma vez, e a frase de deslumbramento ficou sendo uma das brincadeiras de minha família, que de vez em quando me dizia rindo: "Olhe um porco de verdade". 
Passávamos por cavalos belos que esperavam de pé pelo amanhecer.

Eu não sei da infância alheia. Mas essa viagem diária me tornava uma criança completa de alegria. E me serviu como promessa de felicidade para o futuro. Minha capacidade de ser feliz se revelava. Eu me agarrava, dentro de uma infância muito infeliz, a essa ilha encantada que era a viagem diária.

No bonde mesmo começava a amanhecer. Meu coração batia forte ao nos aproximarmos de Olinda. Finalmente saltávamos e íamos andando para as cabinas pisando em terreno já de areia misturada com plantas. Mudávamos de roupa nas cabinas. E nunca um corpo desabrochou como o meu quando eu saía da cabina e sabia o que me esperava.

O mar de Olinda era muito perigoso. Davam-se alguns passos em um fundo raso e de repente caía-se num fundo de dois metros, calculo.

Outras pessoas também acreditavam em tomar banho de mar quando o sol nascia. Havia um salva-vidas que, por uma ninharia de dinheiro, levava as senhoras para o banho: abria os dois braços, e as senhoras, em cada um dos braços, agarravam o banhista para lutar contra as ondas fortíssimas do mar.

O cheiro do mar me invadia e me embriagava. As algas boiavam. Oh, bem sei que não estou transmitindo o que significavam como vida pura esses banhos em jejum, com o sol se levantando pálido ainda no horizonte. Bem sei que estou tão emocionada que não consigo escrever. O mar de Olinda era muito iodado e salgado. E eu fazia o que no futuro sempre iria fazer: com as mãos em concha, eu as mergulhava nas águas e trazia um pouco de mar até minha boca: eu bebia diariamente o mar, de tal modo queria me unir a ele.

Não demorávamos muito. O sol já se levantara todo, e meu pai tinha que trabalhar cedo. Mudávamos de roupa, e a roupa ficava impregnada de sal. Meus cabelos salgados me colavam na cabeça.

Então esperávamos, ao vento, a vinda do bonde para Recife. No bonde a brisa ia secando meus cabelos duros de sal. Eu às vezes lambia meu braço para sentir sua grossura de sal e iodo.

Chegávamos em casa e só então tomávamos café. E quando eu me lembrava de que no dia seguinte o mar se repetiria para mim, eu ficava séria de tanta ventura e aventura.

Meu pai acreditava que não se devia tomar logo banho de água doce: o mar devia ficar na nossa pele por algumas horas. Era contra a minha vontade que eu tomava um chuveiro que me deixava límpida e sem o mar.

A quem devo pedir que na minha vida se repita a felicidade? Como sentir com a frescura da inocência o sol vermelho se levantar? Nunca mais?

Nunca mais.

Nunca.

(LISPECTOR, Clarice. Pequenas descoberta do Mundo. Rio de Janeira: Rocco. 2003. ${ }^{3}$ )

${ }^{3}$ CEREJA, William Roberto. Português: Linguagens, $6^{\circ}$ ano: Ensino Fundamental, $9^{\mathrm{a}}$. edição reformulada. - São Paulo: Saraiva, 2015. p.140-142 
- Realização da leitura de reconhecimento, que deve ser feita silenciosamente pelos alunos.

- Segue um momento de exposição oral pelos alunos do que acharam da história mediada pelo professor (esclarecimento de dúvidas, validação ou não das hipóteses). Exibição de vídeo que traz a leitura do relato (disponível em https://www.youtube.com/watch?v=3m9gMXxoBZw).

-Após esta segunda leitura, os alunos respondem oralmente as seguintes perguntas como verificação de uma preliminar compreensão global do texto: O que é relatado? $\mathrm{O}$ título nos dá informações suficientes para descobrirmos, de imediato, sobre qual o assunto tratado? Quem são os personagens? Como são apresentados? Onde acontecem os fatos? Qual é o tema do relato? Qual a finalidade desse texto?

\subsection{Interpretação}

Atividade 1: Identificação de palavras-chave para compreensão do texto

-Os alunos devem responder as questões sobre o enredo do texto, descobrindo as letras da palavra que preenche os traços corretamente.

1.Embora muito prazerosos os banhos, por que o pai não permitia que demorassem?

2.Sentimento vivenciado pela narradora ao fazer o relato

3.Fase da vida em que os fatos relatados aconteceram...

4.Horário em que ocorriam os banhos.

5.O mar para a menina era algo...

6.Característica do mar segundo a personagem

7.Cidade onde aconteciam os banhos.

8.Pela crença do pai, como deveriam ser os banhos?

9.Como se sente a personagem ao lembrar dos banhos?

10.Pessoa de grande presença no relato da menina...

11.Os banhos para a menina eram momentos de muita....
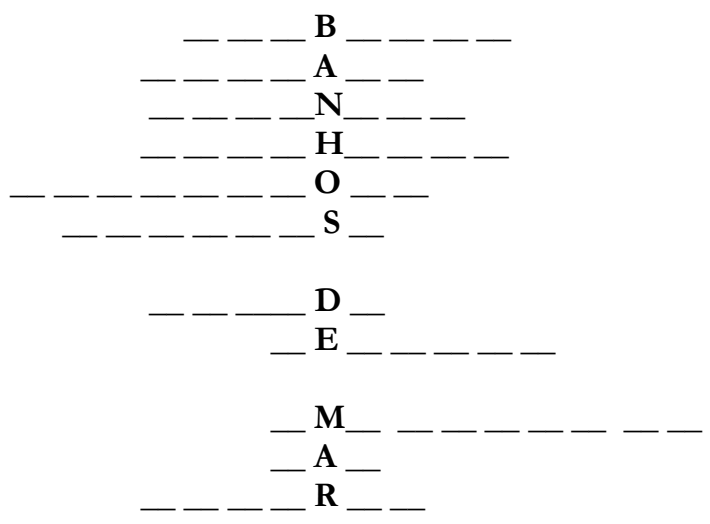

Atividade 2- Questionamento sistemático sobre o texto. 
- O professor pede para os alunos responderem por escrito algumas perguntas sobre o relato, localizando informações explícitas, bem como inferir as informações implícitas no texto em estudo.

1.Que costumes e crenças cultivados pelo pai envolvia o banho de mar?

2.Por que atravessar a cidade ainda escura era algo tão marcante para a narradora?

3.O que representava para a menina a viagem diária às praias de Olinda?

4.Encontre no texto o trecho em que a autora fala do encantamento, do enlevo que ela sentia no contato com o mar.

5.A narradora descreve muitas sensações ao tomar banho no mar. Que sensações eram essa e a que sentidos estavam relacionados?

6.Por que a menina queria se unir ao mar?

-Realizada a tarefa, promover comentário sobre as respostas.

Atividade 3- Ilustrando o conto.

- O professor antecipadamente divide o conto em 5 partes conforme as ações principais e numera-as (1-expectativa da viagem; 2 -a paisagem da viagem de bonde; 3-o mar ; 4-o banho, 5-a volta para casa).

-Divida a sala em 5 grupos.

-Diga em segredo para cada grupo uma parte (número) que eles deverão desenhar.

-Peça que os leiam todo o texto, mas desenhem somente a parte que lhe foi dada.

-Terminados os desenhos, o professor recolhe-os e expõe na lousa, para que os alunos adivinhem que desenho se relaciona com as partes do texto, proporcionando discussão sobre como identificaram.

\subsection{Reflexão sobre a organização linguística e discursiva do relato pessoal} passado

Atividade 1- Reconhecendo efeitos dos pronomes de $1^{\mathrm{a}}$ pessoa e os verbos no

-O professor precisa fazer os alunos perceberem que as escolhas linguísticodiscursivas presentes num dado gênero não são aleatórias, mas são marcas típicas do gênero e de sua função.

-O professor deve selecionar trechos evidenciando os pronomes e os verbos empregados nesse gênero. Por exemplo:

"Chegávamos em casa e só então tomávamos café. E quando eu me lembrava de que no dia seguinte o mar se repetiria para mim, eu ficava séria de tanta ventura e aventura."

- Em seguida propor questões como: "Por que se usa pronomes de $1^{\mathrm{a}}$ pessoa no relato pessoal?", "Que efeitos essa escolha de narrador tem sobre o leitor?; "Por que se emprega verbos no passado nesse gênero?" 
-Essa reflexão é essencial para a escrita do gênero por mostrar facetas de sua constituição enquanto manifestação de uma língua. Portanto, pode ajudar a formar leitores e produtores de textos orais e escritos.

\subsection{Características do relato pessoal}

-O professor aproveitando todos os conhecimentos das leituras feitas pode fechar este módulo esquematizando as característica do gênero em análise, elaborando coletivamente um quadro com as aspectos principais do gênero que servirá para orientar o processo de produção textual.

Quadro 1: Características do gênero relato pessoal

\begin{tabular}{|c|l|}
\hline Propósito & -Relatar episódios marcante na vida de quem escreve \\
\hline Destinatário & $\begin{array}{l}\text {-Pessoas que gostam de ler; pessoas que gostam de lembrar do passado; } \\
\text { pessoas saudosistas }\end{array}$ \\
\hline Conteúdo & -Lembranças, fatos marcantes na vida de uma pessoa \\
\hline \multirow{5}{*}{ Organização } & $\begin{array}{l}\text {-apresenta um título que estimula o leitor para ler } \\
\text {-inicia informando o leitor do fato relatado e sua importância, onde e } \\
\text { quando aconteceu e os personagens envolvidos; } \\
\text {-um narrador personagem, } 1^{\text {a }} \text { pessoa, que conduz a narração, dando } \\
\text { ênfase para as sensações e emoções vividas no passado; } \\
\text {-há descrições de pessoas, lugares e objetos. }\end{array}$ \\
\hline & $\begin{array}{l}\text {-formal ou informal, conforme o autor e o público leitor; } \\
\text {-o texto é subjetivo, tem um tom de saudade, reflexões, desejo de } \\
\text { reviver; } \\
\text {-predomínio de verbos no passado e presença de expressões adverbiais } \\
\text { de tempo e espaço bem-definidos. }\end{array}$ \\
\hline
\end{tabular}

Fonte: Elaborado pela autora.

MÓDULO 2 (6 AULAS): ESCREVENDO E REESCREVENDO RELATO PESSOAL

\subsection{Objetivo}

-Produzir um relato pessoal tendo em vista características do gênero.

\subsection{Produção escrita: "No túnel do tempo"}

-Proposta 1-Escolha uma das fotos (apresentadas no início da sequência) em que você, bem criança, esteja em algum lugar com sua família, colegas de escola ou amigos. Observe com atenção e embarque no túnel do tempo: inspirando-se na foto, relate o que você e as pessoas retratadas faziam naquele momento, de que evento participavam, o que falavam, do que riam, o que acontecia etc.

-Proposta 2- Lembre-se de algum fato que tenha marcado sua vida: uma viagem, uma festa, uma briga, o primeiro dia na escola, um acidente etc. e faça um relate escrito desse acontecimento. 


\subsection{O planejamento do texto}

- O professor deve estimular que o aluno planeje seu relato; o aluno precisa imaginar respostas para as seguintes questões: Que acontecimento vou relatar? Quem participa desse acontecimento? Onde e quando aconteceu? Que impressões quero relatar? Que tipo de linguagem é mais adequado? Quem vai ser o leitor do meu texto? Onde meu texto vai ser lido? Que influência pode sofrer devido à leitura desse gênero? Como pode ser o título?

\subsection{A primeira produção, fazer um rascunho do seu relato}

\subsection{A revisão com os colegas}

\subsection{A primeira reescrita}

\subsection{A mediação sistemática do professor}

-De posse dos relatos escritos dos alunos, o professor deve realizar uma correção, avaliação para os textos voltarem para os alunos, que procederão a uma segunda reescrita; para essas atividades professor e alunos se orientarão pelos critérios a seguir, que serão expostos e comentados na sala.

- O texto apresenta uma linguagem adequada ao gênero?

- O título está adequado ao enredo da história? Mobiliza o leitor para a leitura?

- Estão presentes os elementos da narrativa (personagem, cenário, tempo, conflito e desfecho)?

- O texto apresenta pontuação, paragrafação, concordância, ortografia, acentuação adequadamente?

- O enredo apresenta uma experiência vivida? É subjetivo? Há sequência de acontecimentos marcantes da vida do narrador?

- Há impressões e reflexões sobre o fato protagonista do relato?

- O relato está em $1^{a}$ pessoa?

- Foram usadas expressões para indicar o tempo e o lugar?

- O relato apresenta trechos descrevendo a paisagem, as pessoas e os costumes?

- O relato responde às perguntas: o quê? quem? quando? onde? como? por quê? dos textos.

-Escrita a versão final, o professor conduzirá a etapa de organização e divulgação

\section{MÓDULO 3 (2 AULAS): PREPARANDO A DIVULGAÇÃO DOS TEXTOS}

\subsection{Objetivo}

-Preparar a circulação social do texto produzido pelos alunos.

\subsection{Procedimentos}

-O professor deve dividir os alunos em grupos, distribuir tarefas: organizar os textos, escolher um título (que pode ser "Eu também faço histórias") e ilustrar uma capa 
para a coletânea; escrever uma apresentação, fazer um sumário; se desejarem, ilustrar cada relato, colar uma cópia de foto;

-Dependendo das condições, a coletânea pode digitada ou pode ser mesmo manuscrita, encadernada para fazer parte do acervo da biblioteca;

- Programar para apresentar a coletânea durante uma reunião de pais, com alunos lendo alguns relatos; caso a escola tenha internet, criar um blog para postar os relatos para todos os alunos tomarem conhecimento.

\section{CONSIDERAÇÕES FINAIS}

Este trabalho norteado pelo objetivo de apresentar uma sequência didática com o gênero relato pessoal, como material didático destinado a alunos de $6^{\circ}$ do ensino fundamental para ampliar a competência em leitura e produção textual possibilitou uma reflexão sobre as questões "Como ensinar os alunos a produzirem um determinado gênero textual?"; "O que significa tomar o gênero textual como objeto de ensino?”, levantadas em decorrência da constatação de que, apesar de os professores terem conhecimento de várias práticas recomendadas nos documentos oficiais para ensinar leitura e produção textual, a mobilização desses conceitos para planejar atividades concretas para a sala de aula, articulando as práticas de linguagem como oralidade, leitura/interpretação, escrita e análise linguística, ainda não é uma prática corrente.

É importante dizer que as leituras realizadas para compreensão das questões postas, revelaram que um gênero textual é uma entidade complexa, a começar pela grande variedade de concepções para conceituá-lo e caracterizá-lo. O que, de certa forma, torna compreensível as dificuldades em tomá-lo como objeto de ensino no contexto escolar.

Por esta razão, apresentamos modelos de sequências didáticas, procedimento que propicia um trabalho organizado e sistemático de um determinado gênero textual. Nesse sentido, este trabalho traz para o professor a ideia de que trabalhar com os gêneros no contexto escolar exige certa dose de confiança para não nos limitarmos apenas ao livro didático no tocante às propostas de leitura ou produção textual e elaborar alternativas pedagógicas oriundas do contexto das necessidades dos alunos e da escola.

Além disso, desejamos que os professores para quem este texto se destina, compreendendo os conhecimento aqui expostos, consigam transformar as aulas de "redação" em aulas de produção textual; concebam o ensino da leitura e da escrita como competências que podem ser ensinadas, que a revisão e a reescrita tenham espaço nas salas de aula; que vejam o ler e o escrever como atos, que só têm sentido, se tive propósito comunicativo; que vejam o texto do aluno como um processo e não somente um produto.

Assim, a maior evidência resultante deste trabalho é que ensinar um gênero ou com gêneros, seja escrito ou oral, implica o planejamento e a realização de atividades organizadas sistematicamente, exercícios modulados, pois como "instrumento de comunicação", um gênero não é só uma estrutura textual; um gênero é um discurso, é uma ação e uma forma de organização social, é uma categoria cultural, razão pela qual o professor não pode perder de vista as condições de produção e circulação nas situações reais fora dos muros da escola. 


\section{REFERÊNCIAS}

ARAÚJO, D. O que é (e como faz) sequência didática? Disponível em: $<\underline{\text { http://www.entrepalavras.ufc.br/revista/index.php/Revista/article/view/148. }}$. Acesso em: 14/06/2018.

BRASIL. Ministério da Educação e do Deporto. Parâmetros Curriculares Nacionais, PCN, Lingua Portuguesa, $5^{a}$ a $8^{a}$ séries, SEF-MEC-Brasília: 1998.

BRASIL. Base Nacional Comum Curricular (BNCC). MEC/CONSED/UNDIME, 2017. Disponível em: < 568 http://basenacionalcomum.mec.gov.br/images/BNCC_publicacao.pdf $>$. Acesso em: 02 jan. 2018.

BAKHTIN, Mikhail. Estética da criação verbal. 2. ed. São Paulo: Martins Fontes, 2011.

CEREJA, William Roberto. Português: Linguagens, $6^{\circ}$ ano: Ensino Fundamental. $9^{a}$. edição reformulada. - São Paulo : Saraiva, 2015. p.140-142

DOLZ, J. ; SCHNEUWLY, B. Gêneros escolares. Das práticas de linguagem aos objetos de ensino, In: SCHNEUWLY, B; DOLZ, J. (Orgs.). Gêneros orais e escritos na escola. 2. ed. Campinas, SP: Mercado de Letras, 2004. p. 61-78.

DOLZ, J.; NOVERRAZ, M.; SCHNEUWLY, B. Sequências didáticas para o oral e a escrita: apresentação de um procedimento. In: SCHNEUWLY, B; DOLZ, J. (Orgs.). Gêneros orais e escritos na escola. 2. ed. Campinas, SP: Mercado de Letras, 2004. p. 81-108.

LOPES-ROSSI, Maria Aparecida Garcia. Procedimentos para estudos de gêneros discursivos da escrita. Disponível em:

$<$ http://revistas.pucsp.br/index.php/intercambio/article/view/3680/2405>. Acesso em: 14/06/2018.

MARCUSCHI, Luiz Antonio. Producão textual, análise de gênero e compreensão. São Paulo: Parábola Editorial, 2008.

OLIVEIRA, Andreza de; RODRIGUES, Maria Isaura Pinto. Sequência Didática: uma Proposta para Gêneros da Ordem do Relatar. II Congresso Internacional de Linguística e Filologia; XX Congresso Nacional de Linguística e Filologia.CiFEFiL, Rio de Janeiro: 2016.

OLIVEIRA, M. do S. Gêneros textuais e letramento. Revista Brasileira de Linguística Aplicada, v. 10, p. 325-345, 2010.

PASSARELLI, Lilian Chiaro. Conexão entre pesquisa e prática na sala de aula: do produto para o processo. In: . Ensino e Correção na Produção de Textos Escolares. São Paulo: Telos, 2012. p. 143-175. 


\section{Revista

SANTOS, Carmi Ferraz; MENDONÇA, Márcia; CAVALCANTI, Marianne C. B.(Orgs.). Diversidade textual: os gêneros na sala de aula.1.ed. - Belo Horizonte: Autêntica, 2007.

Recebido em: 12/07/2018 Aprovado em: 25/11/2018

Publicado em: 31/12/2018 